Bol. Acad. peru. leng. 61. 2016 (19-33)

\title{
El soneto de Javier Sologuren como dispositivo poético
}

\section{The sonnet of Javier Sologuren as a poetic model}

\author{
LUIS EdUARDo LiNO SALVADOR \\ Universidad Antonio Ruiz de Montoya \\ Universidad Nacional Mayor de San Marcos
}

\section{Resumen:}

Este trabajo revisa el soneto de Javier Sologuren como un dispositivo poético capaz de dialogar y reformular la práctica de dicha forma de composición fija en el marco de su propia tradición poética y en las condiciones que rodean su actualización en un contexto de enunciación específico.

\section{Abstract:}

This paper revises the sonnet of Javier Sologuren as a poetic model capable of dialogue and reformulate the practice of this fixed composition within the framework of his own poetic tradition and in the conditions around its updating in a specific context of enunciation.

Palabras clave: Javier Sologuren, poesía peruana, soneto, métrica. 
Keywords: Javier Sologuren, Peruvian poetry, sonnet, metric.

Recibido: 31/01/2016

Aceptado: 29/02/2016

Si a una persona le debemos en la década de los cuarenta del siglo pasado un elogioso reconocimiento hacia José María Eguren como poeta fundacional de la poesía peruana moderna, sin duda, esa persona es Javier Sologuren. Si en esta misma línea de una deuda impagable, buscamos al editor que se arriesgó con agudeza y fino acierto a publicar los primeros textos de la mítica generación peruana del sesenta, pues el nombre de dicho editor es también Javier Sologuren. A este modelo de intelectual le debemos, además, valiosas antologías sobre la poesía peruana; así como también esenciales traducciones de diversas tradiciones literarias. A ello también hay que sumar sus sugerentes aproximaciones, las cuales buscaban desentrañar el universo verbal de tres escritores que ahora resultan imprescindibles, nos referimos a Carlos Germán Belli, Washington Delgado y Sebastián Salazar Bondy. Todo este medular legado hace de Javier Sologuren un escritor capital para entender el desarrollo del fenómeno literario peruano. Más aún, si pensamos en la poesía de Javier Sologuren; entonces, esta ocupa un lugar fundamental en dicho legado. En ella se puede encontrar una constante y esta radica justamente en su diversidad, en su huida del lugar común, en su asidua experimentación con distintos tópicos, formas estróficas y, también, 
el cultivo de una poesía clásica. En estas direcciones, su poesía ofrece el trabajo con el verso libre, la ruptura de la linealidad del significante, como es el caso del poema «Viento de vocales» (Sologuren 1999: 150; 2004: 251), el trabajo con la espacialidad de la página cuyo ejemplo se encuentra en el poemario Folios de El enamorado y la muerte (Sologuren 1999: 156-189; 2004: 261-317); asimismo, con el dominio del endecasílabo en sus distintas modalidades y de la elaboración de una forma de composición fija que tiene sobre sí una vasta tradición, nos referimos al soneto.

A lo largo de la obra poética de Javier Sologuren, el soneto ha transitado por toda ella desde sus primeras creaciones poéticas publicadas en Mar nuestro fechada en el año 1942 con dos sonetos de medida silábica alejandrina hasta ocupar un lugar central, privilegiado, en el poemario Catorce versos dicen... (Sologuren 1999: 221-228; 2004: 389-398). El soneto, entonces, es relevante en la lírica del poeta de Vida continua. Por ello, el propósito de este trabajo consiste en realizar una inicial aproximación al soneto de Sologuren desde el enfoque de la versología moderna y de una noción concreta: el soneto como dispositivo poético (Le Corre 2001). Resulta necesario, entonces, señalar qué entiende la versología moderna por dispositivo poético. En primer lugar, se parte de una premisa básica: concebir los versos, las estrofas, las combinaciones de series no estróficas y las formas de composición fija como unidades comunicativas concretas, específicas y altamente socializadas, vale decir, que son identificadas y re-conocidas tanto por una comunidad especializada 
(críticos, creadores) como por un público diverso. En segundo lugar, un dispositivo poético es una estructura métrica-formal altamente comunicativa capaz de rediseñar y recrear la relación pragmática autor-lector pensados como instancias ficcionales. En otros términos, una silva, una lira, una canción, un epigrama, un endecasílabo, etc., o para nuestro caso concreto un soneto, hacen posibles la actualización de un conjunto de posibilidades y realidades de ejecución de dichas formas de composición en su contexto de enunciación o momento ideológico actual. Siendo capaz de hacer dialogar la tradición -que ha labrado tal forma estrófica desde su origen hasta su estabilización, consolidación-, con la modernidad -en la cual es actualizada creativamente, es decir, en el ahora o en su momento de ejecución-; y confrontar así, tensa y dinámicamente, las sensibilidades de creación y recepción que cada una de ellas -tradición y modernidad-manifiestan.

Estudiar los versos, las estrofas, las combinaciones de series o las formas de composición fija como dispositivos de enunciación consistirá en realizar inicialmente un examen de sus características métricas, pero no con la finalidad de verificar cual plantilla si cumple o resulta equivalente al modelo que forjó la tradición; ya que dicho modelo es una abstracción. De lo que se trata al trabajar con los dispositivos de enunciación es que se establezcan sus diferencias, remarcarlas; consiste en comprender cómo opera tal forma estrófica en su nuevo contexto de enunciación y qué nuevas posibilidades rítmicas y semánticas ofrece el dispositivo en el escenario en el que se hace presente. En este sentido, el soneto de Javier Sologuren se inscribe en una vasta tradición, 
desde sus orígenes itálicos, su consolidación hispánica en distintas escuelas y corrientes a lo largo de todos estos siglos con énfasis en el Siglo de Oro y el modernismo. Así, el soneto de Sologuren dialoga con toda esta tradición no con la finalidad de imitarla, sino de re-crearla y ofrecer nuevas posibilidades de ejecución y realización en el presente. Todo ello en el marco del concierto poético peruano de la segunda mitad del siglo $X X$, en el cual se busca hacer coexistir lo experimental con lo clásico y el que llamativamente es también un escenario en el que aparece la sensibilidad de recuperar la práctica de las formas estróficas tradicionales ${ }^{1}$.

Es, como ya se ha indicado, el soneto una forma de composición fija que se forja en Italia. Según Rudolf Baehr, hay muestras consolidadas de la práctica del soneto a partir del año 1194 en el contexto de la corte de Federico II (1981: 391). Para Antonio Quilis, el soneto que conocemos actualmente tanto de manera formal como conceptual se debe al que fue legado por Dante y Petrarca (1989: 132). En el escenario español, las primeras evidencias del soneto datan del siglo XV con la figura del Marqués de Santillana y sus cuarenta y dos sonetos fechos al itálico modo; sin embargo, tuvo que bregar con la práctica predominante de la copla de arte mayor (Baehr 1981: 394). En este panorama, el trabajo de Santillana perdió su verdadero brillo. Fue en el siglo XVI, con Juan Boscán y Garcilaso de la Vega que el soneto en España se consolida; así como también una medida silábica medular: el endecasílabo. Ellos siguen de manera directa el modelo de Francesco

1 Un ejemplo sumamente representativo es la poesía de Carlos Germán Belli. 
Petrarca y tenían también como factor clave que para 1525 la copla de arte mayor fuera empleada en menor medida (Baehr 1981: 395).

De las breves historias del soneto escrito en lengua española que elaboraron tanto Antonio Quilis (1989) como Marcela López Hernández (1998) se puede realizar la siguiente síntesis. El soneto alcanzó un notable esplendor en elSiglo de Oro; especialmente, en el barroco con los nombres representativos de Lope, Góngora y Quevedo (Quilis 1989: 134). En el siglo XVIII la práctica del soneto queda relegada, ya no resulta valorada y son pocas las muestras de su cultivo (López 1998: 14). El siglo XIX ofrece un paulatino resurgimiento del soneto. Sin embargo, para que esta forma de composición fija recupere su lugar privilegiado, se debió esperar la llegada del modernismo. Asimismo, esta corriente literaria no solo constituyó la recuperación del soneto, también fue el momento en el cual se desarrolló la mayor diversidad de sus variaciones o actualizaciones en su organización métrico-formal. Entre las principales se encuentran, en primer lugar, el trabajo con la incorporación de rimas a la manera francesa en los cuartetos $A B A B-$ $A B A B$. En segundo lugar, la modificación de la rima en el segundo cuarteto también de influencia francesa ABBA-CDDC. Esto trajo como consecuencia el aumento y variedad del número de rimas ofreciendo ahora un total de siete. Tercero, la elaboración de metros diversos en su composición («Verano» de Manuel Machado con versos trisílabos y alejandrinos, etc.) y hasta la heterometría en el interior de sus estrofas («Estío-juventud» de Manuel Machado con versos alejandrinos, bisílabos, heptasílabos, pentasílabos, etc.). 
En el contexto del posmodernismo se desarrolla una práctica generalizada del soneto circunscribiéndose al empleo de su estructura clásica. La Generación del 27, según señalan Quilis y López Hernández, fue la que cultivó sobremanera el soneto en tal modalidad. Por otro lado, Arcadio Pardo señala que, en el contexto español del siglo XX, el soneto clásico «se impone con su estructura más rigurosa; antes y después de la guerra civil española» (2014: 129). Es decir, en España la forma tradicional del soneto impera desde dicho momento hasta el presente y cita como ejemplos los Sonetos espirituales de Juan Ramón Jiménez que datan de 1916, los Sonetos amorosos de Germán Bleiberg de 1936 hasta Esta espina dorsal estremecida, sonetos de Sagrario Torres del 2007 o los de Carlos Murciano en Amatorio del 2010. Lo llamativo es que, ante este panorama clásico del soneto en España, el mismo Arcadio Pardo subraya que es en Hispanoamérica donde se ha producido la mayor experimentación entre novedades y variantes del soneto y que van más allá del modernismo (2014: 130); sin que ello haya limitado el cultivo del soneto tradicional.

Esta es la vasta tradición o el panorama en el cual se inscribe el soneto de Javier Sologuren. Así como también es el escenario en el que se produce la coexistencia entre el trabajo con el soneto clásico y las novedades, variantes, que sobre esta forma de composición fija se han llevado a cabo. El soneto de Sologuren como dispositivo es también esa coexistencia entre lo clásico y lo innovador. No es una repetición de una forma abstracta, sino es la re-creación o re-escritura de una forma clásica en el contexto de la lírica peruana 
del siglo XX. Leer el soneto de Sologuren es establecer la relación tensa y dinámica entre la tradición y la modernidad. Los primeros sonetos que publica son los dos ya aludidos en Mar nuestro de 1942 al lado de Deustua y Jorge Eduardo Eielson. Observemos sus dos sonetos:

Pero si me dijeras donde comienza el mar llano, ensombrecido viajero de mis sueños agitados y extensos; porque me hallo sin leños donde poner las manos y mis ojos salvar.

Tan solo me indicases un camino sin vientos en que el agua se empoce sin detener mis pasos mordidos de luz rala. ¡Son tan pobres y escasos los recuerdos de ese mar que apetezco! Van lentos

tus cuidados viajero. No escuchas ya mis ruegos crecidos en la sombra de tu frente lunada como concierto de olas de la mar desterrada.

Pero aunque me dijeras... En tus recientes fuegos de sal y de occidente tan pronto el alma crece que pronta ha rebalsado la mar que no perece.

II

Y vuelve a ser el alba de espuma entre tus manos -líquidas e inquietantes transparencias- las mañanas suspendidas de mis ojos, plenas de tempranas, tersas imágenes bienhalladas en tus llanos

rumorosos. $Y$ hacia su ser vuelven claridades de velas y de aves, cal naciente y escogida 
flor. ¡Oh fresca mar, de limpias olas, sorprendida siempre y ahora, en tu extensión y sola! Ya invades

los mil cielos combatientes de la rosa dada al vuelo sin sosiego. Tu pulso se acelera $\mathrm{y}$ encuentro que en tu dorso la vida se quisiera

replegar y expandirse, y ser todo en la nada. Mar, cotidiano fervor de sales y de espumas en brillo de tus soles y en apagadas brumas.

(Sologuren 2004: 635-636)

Lo llamativo de estos dos sonetos radica en su trabajo con el verso de catorce sílabas métricas o denominado alejandrino, así como también con la misma disposición y juego de rimas consonantes que en total llegan a ser siete combinaciones por cada soneto. Este hecho es importante porque permite pensar en una estructura muy similar a la realizada en el contexto modernista; sin embargo, el lenguaje empleado en su soneto se aleja categóricamente del léxico preciosista. Esta relación entre el recipiente y el contenido tiene su punto inicial con los sonetos de Valdelomar, cuya arquitectura métrica formal es marcadamente modernista; pero el léxico y el universo representado se oponen a su construcción formal. Estos dos sonetos primeros comparten también otras características. Una de ellas es el trabajo con el encabalgamiento abrupto y el suave (Quilis 1989: 85), que operan tensamente entre la ruptura del continuo del verso y su dejarlo fluir que se extiende hasta más allá de la quinta sílaba del verso inmediato o incluso en toda su extensión. Otra característica es el empleo de amplificadores expresivos como 
es el caso de los signos de exclamación presentes en el segundo cuarteto de ambos sonetos y que abarcan respectivamente el tercer y cuarto verso.

Luego de estos dos, Sologuren publicará sonetos que abandonan la medida silábica alejandrina por el empleo del endecasílabo. Así, los sonetos que aparecerán en sus poemarios El morador, El diario de Perseo, Regalo de lo profundo, La gruta de la sirena o los de sus Catorce versos dicen... desarrollan diversas actualizaciones del endecasílabo y sus modalidades enfática, melódica, heroica o sáfica. Todas ellas coexisten y en ellas puede fundarse la invariante del verso de Sologuren, vale decir, en su diversidad. Ello nos conduce también a señalar que la organización de los tiempos marcados en sus versos se fundamenta en la pluriacentualidad, que es característica de nuestra conciencia rítmica (Belic 2000: 513). No hay un esquema rígido, un patrón o norma que someta la realización de dichos tiempos marcados o que se siga de manera rigurosa como modelo. Ello no quiere decir que la diversidad y la flexibilidad atenten contra el plano rítmico de sus sonetos. Por el contrario, Sologuren hace de lo variable y de lo plural la base para la construcción del movimiento rítmico de sus sonetos; del mismo modo se podría extender esta idea a su obra poética en general.

Las rimas con las que trabajará Sologuren en su obra posterior ya no recogen las siete posibilidades combinatorias de sus dos primeros sonetos. Sus rimas operarán en total con las habituales cuatro o cinco. Aquellas que conforman los cuartetos emplean solo dos juegos de rimas cuya disposición es constantemente 
abrazada: ABBA-ABBA y ABBA-BAAB; con dos notables excepciones que enriquecen su plasticidad: nos referimos al soneto «El morador», del libro que lleva el mismo título, con su disposición AAAA-BCBA y al soneto "Contra el vacío» de Catorce versos dicen... organizados de la siguiente manera: ABAB-CDCD. En lo que respecta a los tercetos, sin duda, estos ofrecen una notable variedad y flexibilidad; por ello resultaría poco efectivo establecer una tendencia sobre su disposición. Preciso es señalar que existe un ligero predominio de las rimas consonantes sobre las asonantes.

En lo que respecta al estatuto del circuito comunicativo que diseñan sus sonetos, es posible señalar la presencia de un locutor personaje o que se autorrepresenta con la finalidad de dirigir su enunciado e incluso apelar hacia un alocutario representado que se hace manifiesto en cualquier modalidad de la segunda persona. Asimismo, el locutor del poema también tiende a representar y valorar el mundo externo ${ }^{2}$.

El soneto de Javier Sologuren como dispositivo poético construye, entonces, sus condiciones formales y a la vez su propio espacio desde el cual enunciar; así, diseña su lugar en la tradición del soneto hispánico y, específicamente, peruano. En nuestro país, el soneto es una forma de composición fija fuertemente arraigada en nuestra tradición lírica. Nombres como los de Ricardo Palma, Manuel González Prada, José Santos Chocano, César Vallejo, Abraham Valdelomar, Martín Adán, entre otros, labran dicha tradición. Sin

2 Antonio García Berrio realiza un importante abordaje sobre los sujetos del soneto en su artículo «Estatuto del personaje en el soneto amoroso del siglo de oro» (1980). 
embargo, aún carecemos de un estudio histórico del soneto en el Perú, de las variedades, actualizaciones o re-escrituras de este importante dispositivo poético. En ese breve esbozo de la tradición del soneto en nuestro país, se sitúa también la práctica del verso libre acompañado de un, a veces, explícito rechazo a las formas estróficas tradicionales. Es este espacio en conflicto desde el cual se enuncia el soneto de Sologuren con su diálogo entre la tradición y la modernidad. Él mismo hace de su obra en general la clara muestra de tal diálogo al hacer coexistir, convivir, sus sonetos con la más ferviente experimentación sobre el verso y las estrofas.

La década de los ochenta en el Perú está dominada por el verso libre, el registro coloquial, la poesía conversacional, por el ingreso de un lenguaje virulento al léxico del poema ${ }^{3}$. En ese contexto, Sologuren publica en 1987 sus Catorce versos dicen..., libro que reúne un breve grupo de poemas organizados en dos cuartetos y dos tercetos: sonetos que no reciben su denominación en cuanto tal. Como título, el libro resulta valioso, pues en un escenario de extremismo versolibrista, Sologuren hace «hablar» a sus versos con una de las formas estróficas más tradicionales. Pero ese grupo de poemas llevan a cabo la más importante de las actualizaciones o re-escrituras del soneto. Nos referimos a la ausencia total de signos de puntuación que permite que el verso fluya sin ruptura alguna y que su lectura

3 Sobre las características de la lírica de los años ochenta, remitimos al valioso prólogo que elaboran José Antonio Mazzotti y Miguel Ángel Zapata para la antología El bosque de los huesos (1995). 
sea la más cercana al fluir de la oralidad, al habla. Esto quiere decir que el lector diseñe el movimiento o el ritmo de lectura del poema sin las ataduras de las pausas convencionales o sintácticas. Esta ausencia de puntuación más cercana al verso moderno, al fluir surrealista, ingresa al espacio del soneto, al espacio de una forma clásica, y mutuamente se reescriben. El soneto de Sologuren en Catorce versos dicen... es un dispositivo poético de enunciación: tradición, modernidad, escritura y lectura se despliegan en su espacio poético. Apreciemos el poema «(sueñas/velo)» de Catorce versos dicen...:

mueve el cuerpo desnudo su marea en su cerrada red corre la sangre los espejos del sueño se deslizan todo gravita como un mundo aparte

duermes y estoy desde mi propio canto sintiendo en ti la cálida resaca la delicada combustión del aire esa extrañeza que se torna estatua

duermes y estando junto a ti me encuentro solo atrapado en la profunda noche vigía desvariado y al acecho

eres un mar cerrado y mientras duermes y estoy a tus orillas y me tienes presente en tu confianza y tan ajeno

(Sologuren 1999: 227; 2004: 395)

Escribir utilizando sonetos en el contexto de la lírica de los ochenta en el Perú puede resultar anacrónico, pero 
le permite a Sologuren recontextualizar la enunciación y, por tanto, buscar un lector/oyente para sus sonetos con nuevos códigos. Tomando las palabras de Herve Le Corre sobre los lieder de José María Eguren, se puede afirmar que el soneto de Javier Sologuren «como dispositivo poético propone nuevos protocolos de transmisión y de escucha en un marco intertextual también polifónico» (2001: 279).

El soneto de nuestro poeta, entonces, ingresa al concierto de la coralidad de diversas propuestas sobre el verso en el contexto de la lírica peruana en el que lo clásico y lo moderno despliegan sus horizontes culturales para dialogar y mutuamente reescribirse. 


\section{Bibliografía}

BAEHR, Rudolf. Manual de versificación española. Madrid, Gredos, 1981 [1970].

BELIC, Oldrich. Verso español y verso europeo. Una introducción a la teoría del verso español en el contexto europeo. Santafé de Bogotá, Instituto Caro y Cuervo, 2000.

GARCÍA BERRIO, Antonio. «Estatuto del personaje en el soneto amoroso del Siglo de Oro», en Lexis. Vol. 4. No 1. Lima, 1980, págs. 61-76.

LE CORRE, Herve. «Los Lieder de José María Eguren (18741942) como dispositivo poético», en Signa. No 10. Madrid, 2001, págs. 269-293.

LÓPEZ HERNÁNDEZ, Marcela. El soneto y sus variedades. (Antología). Salamanca, Ediciones Colegio de España, 1998.

MAZZOTTI, José Antonio y Miguel Ángel ZAPATA (eds.). El bosque de los huesos: antología de la nueva poesía peruana 19631993. México D. F., Ediciones el Tucán de Virginia, 1995.

QUILIS, Antonio. Métrica española. Edición corregida y aumentada. Barcelona, Editorial Ariel, 1989 [1984].

PARDO, Arcadio. «De la diversidad del soneto», en Rhythmica. Revista española de métrica comparada. No 12. Sevilla, 2014, págs. 127-172.

SOLOGUREN, Javier. Vida continua. Nueva antología. Valencia, Pre-Textos, 1999.

. Obras completas de Javier Sologuren I. Vida continua.

Lima, Pontificia Universidad Católica del Perú, 2004. 